\title{
Hipnoz ve bilimde kullanım alanları
}

\section{Hypnosis and areas of usage in science}

\author{
Ahmet Telli
}

Sağlık Bilimleri Üniversitesi, Sağlık Bilimleri Enstitüsü, Geleneksel ve Tamamlayıcı Tıp Anabilim Dalı, İstanbul, Türkiye

Cite this article as / Bu makaleye atıf için: Telli A. Hipnoz ve bilimde kullanım alanları. J Med Palliat Care 2020; 1(4): 109-112.

\begin{abstract}
ÖZ
Hipnoz, kişinin farkındalığı korunarak iç deneyimlerine yöneldiği ve telkin kabul edebildiği bir durum olarak kabul edilmektedir. Yapılan çalışmalar hipnozun sinirsel korelasyonları hakkında kapsamlı bilgiler sunmakla birlikte hipnoz çalışmaları karmaşıktır. Bağlam, beklenti ve kişilik gibi birçok faktör, hipnotik yanıtı ve kullanılan önerileri etkilemektedir. Hipnoz günümüz tıp dünyasında aneljezi ve ağrı yönetimi, davanmış ve kaygı bozuklukları, cinsel işlev bozuklukları, diş hekimliği problemleri, bağımlılık vb. gibi durumlarda tedavi ve terapi amacıyla sıklıkla kullanılmaktadır. Hipnoz, güncel bilgiler rehberliğinde tıp, diş hekimliği ve ruh sağlı̆̆ı profesyonellerinin tedavi ve terapilerde elini güçlendirebilecek çok değerli bir uygulama olarak kullanılmaktadır.
\end{abstract}

Anahtar Kelimeler: Hipnoz, telkin, duygu, biliş

\begin{abstract}
Hypnosis is considered as a situation that a person can accept suggestions where he keeps his awareness and turns towards his inner experiences. Studies provide comprehensive information about the neural correlations of hypnosis. Hypnosis studies are complicated in this sense. Many factors, such as context, expectation, and personality, affect the hypnotic response and the recommendations used. In today's medical world, hypnosis is frequently used for treatment and therapy in cases such as analgesia and pain management, behavior and anxiety disorders, sexual dysfunction, dentistry problems, addiction. Hypnosis is used as a valuable application that can strengthen the hand of medicine, dentistry and mental health professionals in the treatment and therapies under the guidance of current information.
\end{abstract}

Keywords: Hypnoses, suggestion, emotion, cognition

\section{GíRiş}

Hipnoz, kişinin dikkatinin ve odağının yakın çevresinden ayrıştığ 1 ; duygular, biliş ve imgelem gibi iç deneyimlere çevrildiği uyanık farkındalık durumu olarak tanımlanmakta ve verilen telkinlere uyum olarak kabul edilmektedir (1,2). Hipnoz kelimesinin tanımı Antik Yunan'da uyku karşıllı̆̆ olsa da hipnotik durumunun aslında bir uyku hali olmadığı bilinmektedir. Hipnoz kullanımı tarihinin Yunanlıların inşa ettiği uyku tapınaklarına kadar dayandığı düşünülmektedir. Bilimsel hipnozun kullanımı ise Franz Antoine Mesmer ile 1765 'te başlamıştır. İlk olarak; 1784 yılında cerrahi operasyonlar sirasinda Marquis de Puysegur bilimsel

hipnozu kullananlar arasındadır (3). 1837 yılında ise hipnoz; John Eliot tarafından mezmerik anestezi ile birçok operasyonda kullanılmıştır. Hipnozu cerrahi operasyonlarda başka kullanan kişi ise İskoç cerrah James Esdailedir ve bu konuda bir kitap yazmıştır (4). Sigmund Freud'da hipnozu bir dönem kullananlar arasında olup, daha sonra psikanalize geçiş yapmıştır. Aynı yıllarda Milton Erickson psiko-analizi reddederek hayatının 50 yılını hipnoz çalışmaya ve pratiğine adamış bir kişidir ve literature "Ericksonian hipnoz" terimini kazandırmıştır (5). Ülkemizde ise hipnoz 1935 yılında Janet'in kitabının Cemil Sena Ongun tarafından çevrilmesiyle başlamıştır. 
Daha sonraki yıllarda Dr. Bedri Ruhselman tarafından hipnoz hakkında bir yayın yayılanmıştır ve takiben Dr. Sevil Akay tarafından 1950 de hipnozla tonsillektomi yapılarak, bilimsel hipnoz başlamıştır. 1951-1979 yılları arasında Dr. Hüsnü İsmet Öztürk "Bilinçli Hipnoz" tekniğini kullanarak 2000 hastayı hipnotize etmiştir ve bununla birlikte; hipnoz tekniği ile 250'den fazla hastada sadece hipnoanestezi kullanarak cerrahi operasyonlar gerçekleştirmiştir $(6,7)$.

Hipnoz günlük hayatımızda doğal bir şekilde yaşadığımız trans durumlarında mevcuttur. Örneğin; iyi bir kitabın sayfalarını okurken, nasıl olduğunu hatırlamaksızın tanıdık bir yoldan aşağı inerken, dua ederken ya da meditasyon yaparken hipnozu yaşamaktayız. Aslında hipnoz monoton veya yaratıcı bir faaliyet yürütürken günlük deneyimimizin bir parçasıdır (1). Hipnotize edilirken telkinlere yanıt verme ve uyma yeteneği; hipnotik duyarlılık olarak adlandırılmaktadır. Her insanın hipnotik müdahaleye aynı derecede tepki vermediği bilinmektedir. Hipnotik duyarlılıkları tespit etmeye yönelik standardize edilmiş testler bulunmaktadır. Hipnotik duyarlılık testleri arasında bulunan testlerden biri de Stanford Hipnotik Duyarlılık Ölçeği ve Harvard Grubu Hipnotik Duyarlılık Ölçeğidir. $\mathrm{Bu}$ testlerin dezavantajı istenildiği zaman yapılamaması ve uygulama için belirli bir saatin gerekli olduğudur (8). Yakın zamanda klinik ve araştırma ortamlarında kullanılmak üzere kısa ve pratik uygulama için Elkins Hipnotize Edilebilirlik Ölçeği geliştirilmiştir (9). Bu ölçekle birlikte; daha eski ve daha uzun ölçümlere nispeten daha kısa zamanda güçlü korelasyonlar sağlanmıştır. Türkiye'de ise Dr. Kenan TAŞTAN ve ark. (10) tarafından yapılan çalışmada "Taştan Duyarlılık Ölçeği” pratiğe girmiş ve klinik ortamda çok kısa sürede pratik uygulama imkânı sağlamıştır. Bu ölçeğin ortalama uygulama süresi 5,0+/-1,2 dakika arasındadır. Yapılan çalışmalarda bu testin güvenilir ve hızla uygulanabilir olduğu belirtilmiştir. Kişilerin hipnotik telkinlere tepki verme süresi ile hipnotik duyarlılık arasında bir ilişki olduğu bildirilmiştir. Ancak; bu ilişkiye beyin aktivitesindeki belirgin değişikliklerin eşlik edip etmediği netleştirilememiştir (11).

Landry ve ark. (12) hipnozun sinirsel korelasyonları hakkındaki iyi ve kapsamlı bilgiler sunmaktadır. Hipnoz çalışmaları karmaşıktır; bağlam, beklenti ve kişilik gibi birçok faktör, hipnotik yanıtı ve kullanılan önerileri etkilemektedir $(1,13)$. Beyinde sağ ve sol iki serebral hemisfer vardır ve normal uyanma durumundayken, sol beyin daha dominant olma eğilimindedir. $\mathrm{Bu}$ kısım sözlü olarak iletișim kurar ve daha entelektüel, bilinçli ve mantıklı olmamızı sağlayan bir parçamızdır. Rahatlama esnasında ya da herhangi bir şeye derinden dahil olduğumuzda, sağ beynimiz daha dominant hale gelmektedir. Sağ beyin, semboller ve imgelerle iletişim sağlayan bizim daha duygusal, yaratıcı olmamızı sağlayan kısmımızdır ve 'bilinçdışı zihnimiz' olarak görülmektedir. Örneğin; kendimizi üzülme, endişelenme esnasında hep dirençli hissederiz, çünkü kelimeler zihnin doğru dili değildir. Ancak hayal veya metafor kullanarak resimli bir kelime dili oluşturabilir ve doğru hamleyi yapabiliriz. $\mathrm{Bu}$ açılama beynin hemisferlerinin nöral işlemlenmelerini çok basitleștirse de hipnozun çalışma mekanizmasının açıklanmasında basit ama yararlı bir yöntemdir (1).

Nörogörüntüleme çalışmaları, telkine yanıtta sübjektif değişikliklerin, söz konusu spesifik beyin bölgelerindeki ilgili değişikliklerle ilişkili olduğunu göstermiştir $(14,15)$. Bir kişi hipnozda bir şey hayal ettiğinde (renk, ses, fiziksel aktivite ve ağr1), son bulgular bize beynin benzer alanlarının kişinin gerçekten bu deneyimi yaşıyormuş gibi aktive olduğunu gösterir. Derbyshire ve ark. (16) hem fiziksel olarak uyarılan hem de hipnotik olarak uyarılan ağrının, klasik 'ağrı matrisi' ile ilişkili alanlardaki aktivasyonlara eşlik ettiğini göstermiştir. Başka bir çalışmada ise hipnoz esnasında fonksiyonel manyetik rezonans görüntüleme (fMRI), pozitronemisyon-tomografi (PET) ve elektroensefalografi (EEG) kullanılarak beyin-plastisite değişiklikleri incelenmiş ve hipnozun korku devresine karşıllk gelen bölgelerin tepkisini önlemede güçlü ve başarılı bir yöntem olduğuna dair kanıt bulunmuştur (17).

Hipnoz kendi başına bir terapi olarak değerlendirilemeyebilir, ancak bir şırınga misali ilaçların enjekte edilmesine aracilı edip tedavinin verilmesini kolaylaştıran bir araç olabilir. Hipnoz imkansızı mümkün hale getirmez, fakat hastaların kendilerine inanmalarına ve elde edebilecekleri şeylere deneyimlemelerine yardımcı olabilir (1). Hipnoz günümüz dünyasında terapötik amaçla yaygın olarak kullanılmıştır. Hipnozun tıp dünyasında kullanımı çok geniş ve birbirinden farklı konularda olabilmektedir. Bunlar:

- Hipnoanaljezi: Migren, yanık, terminal evre kanser, doğum, diş hekimliği, genel ve lokal anestezi, premedikasyon, trigeminal nöralji vb. ağrılı durumlarda.

- Davranış bozuklukları: Kekemelik, tikler, yeme bozuklukları, tırnak, fobi, sigara-alkol kontrolü, obsesif kompulsif davranışlar, kaygı, uykusuzluk.

- Sosyal hipnoterapi: Çalışma alışkanlıkları, kendinden şüphe, kilo kaybı tedavisi, heyecan, sinirlilik, spor konsantrasyonu ve performans arttırma,

- Cinsel işlev bozuklukları: Vajinismus, erektil disfonksiyon, prematür ejekülasyon vb.

- Diğer tıbbi durumlar: Siğiller ve basit dermal problemler, bulanti-kusma $(6,7)$. 
Hipnozun yaygın olarak kullanıldığı alanları aşağıdaki başlıklar altında toplayabiliriz.

\section{Ağrı ve Anestezide Hipnoz}

Hipnoz anestezi ve ağrı yönetiminde uzun yıllardır etkili bir şekilde kullanılmaktadır. 1906 yılında Magaw (18), Mayo Clinic’te gerçekleştirilen 14.000 ameliyatın hipnoz ve kimyasal anestezinin kombine edilmesiyle rapor edildiğini bildirmiş̧tir. Ağrllı durumlarda hipnoz kullanımı çok yaygın ve etkindir. 2010 yllında, Amerikan Psikoloji Derneği (David Patterson) (19) tarafından Ağrı Kontrolünde Klinik Hipnoz kitabı yayınlanarak; yanık, debritman, doğum ağrısı, kemoterapi sonrası ağrı vb. gibi durumlarda hipnozun mevcut bakım standardına eşit olduğunu ve çalışmaların birçoğunda hipnozun, dikkat kontrolü, gevşeme-rahatlama, duygusal destek içeren bakım standartlarından veya diğer tedavi kontrollerinden faydalı olduğu belirtilmiştir.

\section{Obstetrikte Hipnoz}

Doğum sancılarını ve ağrılarını azaltma, doğum ile oluşabilecek anksiyete ve korkuları düzenleme vb. gibi durumlar olmak üzere obstetrikte hipnoz çok sık başvurulan bir yöntemdir. Ralph August (20), 19571958 ylllarında 295 bebeğin doğumunu kolaylaştırmak için klinik hipnoza başvurmuştur. Olguların \%94'ünde hipnozun tek başına anestezi formunda olduğu gözlemlenmiştir. Olguların kalan \%6'sında ise hipnotik anestezinin yeterli olmayıp lokal veya genel anestezi ile desteklenmesi gerektiği tespit edilmiştir (21).

\section{Diş Hekimliğinde Hipnoz}

Hipnozun kullanımına diş hekimleri çok sık ve yaygın olarak başvurmaktadırlar. Hipnoz, diş hekimleri tarafından bruksizm, diş prosedürleri, aşırı gag refleksi, orofasiyal ağrıların tedavisi, kanama ve tükürük salınımı azaltmak ve prosedürel ağrıyı yönetmek için çok etkili ve kolayca uyumlanabilen bir şekilde kullanılmaktadır $(22,23)$.

\section{Kronik Ağrılarda Hipnoz}

Fibromiyalji, kronik baş ağrıları, kansere sekonder ağr1, sırt ağrısı, sinirlilik vb. gibi kronik koşullarda Patterson 14 kontrollü hipnoz çalışmasını (12 randomize) kapsayan kronik ağrıyla alakalı bir tablo sundu. Çalışmalar hipnozun grup desteği, bio-feedback, ilaç, gevşeme-rahatlama, dikkat kontrolü ve bilişsel davranış̧̧ı terapiyi içeren standart bakımlara eşit veya daha iyi olduğunu belirtmiştir (19).

\section{Kaygıda Hipnoz}

Kaygı bozukluklarının tamamında çok yaygın şekilde hipnoz kullanılmakta ve semptomları yönetmede, kabullenmede diğer terapi yöntemleriyle çok rahat entegre edilebilmektedir. Kaygıya neden olan örtülü anlamlara ulaşmada çok etkili bir araçtır (24). Ayrıca kaygı bozukluklarının tedavisinde hipnozun tek başına kullanılmaktan ziyade diğer terapi yöntemleriyle birlikte kullanımının daha iyi sonuçlar verdiği belirtilmiştir (25).

\section{Yeme Bozukluklarında Hipnoz}

Obezite, kontrolsüz yeme, anoreksia nervoza, bulumia vb. yeme bozukluklarındaki duygusal boşlukların düzenlenmesinde ve o duyguya neden olan anı ya da travmanın kökenine inme konusunda hipnozla çok başarılı sonuçlar alınmıştır. Hipnozun bu konuda tedaviye anlamlı katkısı mevcuttur (26).

Özetle, hipnoz, güncel araştırmalar gözardı edilmeden ve kanıta dayalı hipnoz protokolleri takip edildiği takdirde tıp, diş hekimliği ve ruh sağllğ 1 profesyonellerinin tedavi ve terapilerde elini güçlendirebilecek çok değerli bir uygulama olmaktadır. Türkiye'de hipnozun daha yaygın kullanımı ve kabul görmesi adına akademik ve klinik çalışmaların teşvik edilmesi ve arttırılması gerekmekte olup, bu alanda daha çok araştırmaya ihtiyaç duyulmaktadir.

\section{ETIKK BEYANLAR}

Hakem Değerlendirme Süreci: Harici çift-kör hakem değerlendirmesi.

Çıkar Çatışması Durumu: Yazarlar bu çalışmada herhangi bir çıkara dayalı ilişki olmadığını beyan etmişlerdir.

Finansal Destek: Yazarlar bu çalışmada finansal destek almadıklarını beyan etmişlerdir.

Yazar Katkıları: Yazarların tümü; makalenin tasarımına, yürütülmesine, analizine katıldıklarını ve son sürümünü onayladıklarını beyan etmişlerdir.

\section{KAYNAKLAR}

1. Williamson A. What is hypnosis and how might it work? Palliat Care 2019; 31. Doi: 10.1177 / 1178224219826581

2. Uran B. Hipnozun Kitabı, Pusula Yayıncılı, Ankara, 2018.

3. Flynnz N. "Hypnosis and Medicine: An Historical Examination. CTCMI 2019; 3: 1-7.

4. Ernst W. Colonial psychiatry, magic and religion. the case of mesmerism in British India Hist Psychiatry 2004; 15: 57-71.

5. Feldman JB. The work of Milton Erickson: a multisystem model of eclectic therapy. Psychotherapy 1985; 22: 154-62.

6. Müezzinoğlu AE. Tibbi hipnoz ders notları. Turkuaz Yayınları. Ankara, 2008.

7. Lee JS, Young YP. Use of hypnosis in the treatment of pain. Korean J Pain 2012; 25: 75-80.

8. Wagstaff GF, Cole JC, Brunas-Wagstaff J. Measuring hypnotizability: the case for self-report depth scales and normative data for the Long Stanford scale. Int J Clin Exp Hypn 2008; 56: 119-42.

9. Kekecs Z, Bowers J, Johnson A, Kendrick CE, Elkins G. The Elkins hypnotizability scale: assessment of reliability and validity. Int J Clin Exp Hypn 2016; 64: 285-304.

10. Tastan K, Demiroz HP, Oztekin C, Sincan S. Development and validation of a Turkish hypnotic suggestibility scale. J Pak Med Assoc 2019; 69: 1236-330.

11. Moss D, Willmarth E. Hypnosis, anesthesia, pain management, and preparation for medical procedures, Ann Palliat Med 2019; 8: 498-503. 
12.Landry M, Lifshitz M, Raz A. Brain correlates of hypnosis: a systematic review and meta-analytic exploration. Neurosci Biobehav Rev 2017; 81: 75-98.

13. Jensen MP, Jamieson GA, Lutz A, et al. New directions in hypnosis research: strategies for advancing the cognitive and clinical neuroscience of hypnosis. Neurosci Conscious 2017; 3: nix004.

14. Cojan Y, Waber L, Schwartz S, Rossier L, Forster A, Vuilleumier P. The brain under self-control: modulation of inhibitory and monitoring cortical networks during hypnotic paralysis. Neuron 2009; 62: 862-75.

15.Demertzi A, Vanhaudenhuyse A, Noirhomme Q, Faymonville ME, Laureys S. Hypnosis modulates behavioural measures and subjective ratings about external and internal awareness J Physiol Paris 2015; 109: 173-9.

16. Derbyshire SWG, Whalley MG, Stenger VA, Oakley DA. Cerebral activation during hypnotically induced and imagined pain. Neuroimage 2004; 23: 392-401

17. Halsband U, Wolf TG. Functional changes in brain activity after hypnosis: neurobiological mechanisms and application to patients with a specific phobia-limitations and future directions. Int J Clin Exp Hypn 2019; 67: 449-74.

18. Magaw A. A review of over 14 thousand surgical anesthesias. Surg Gynecol Obstet 1906; 3: 795-7.

19. Patterson DR. Clinical Hypnosis for Pain Control. Washington, DC: American Psychological Association, 2010.

20. August RV. The obstetrician and hypnosis. Am J Clin Hypn 1959; 1: 151-4.

21. August RV. Hypnosis in obstetrics: Obstetric hypnoanesthesia. New York: McGraw-Hill, 1961.

22. Armfield JM, Heaton LJ. Management of fear and anxiety in the dental clinic: a review. Aust Dent J 2013; 58: 390-407.

23. Facco E, Zanette G, Casiglia E. The role of hypnotherapy in dentistry. SAAD Dig 2014; 30: 3-6.

24. Alladin A. Kaygı bozukluklarının tedavisinde bütüncül BDT. Ed. Özakkaş T. Psikoterapi Yayınları, 2016.

25. Valentine KE, Milling LS, Clark LJ, Moriarty CL. The efficacy of hypnosis as a treatment for anxiety: a meta-analysis. Int J Clin Exp Hypn 2019; 67: 336-63.

26. Mantle F, Eating disorders: the role of hypnosis. Paediatr Nurs 2003; 15: 42-5. 